\title{
La libertad de expresión y la parodia en el derecho a la propiedad intelectual
}

\author{
Betzabé Marciani Burgos* \\ Raúl Solórzano Solórzano*
}

\section{Introducción}

El presente artículo constituye un acercamiento al tema de la parodia y sus implicancias en el campo de la propiedad intelectual, así como sus posibles vinculaciones y conflictos con el derecho a la libertad de expresión. Su elaboración responde a la constatación de dos circunstancias concretas: de un lado, la falta de investigaciones sobre este tema en el Perú, que contrasta con su importante y prolífico desarrollo en otros países, principalmente en los Estados Unidos de Norteamérica, y de otro lado, la verificación fáctica del uso - y eventual abuso - del recurso de la parodia, principalmente por medio de la publicidad comercial, lo que contrasta con su prácticamente nula invocación como mecanismo de defensa en casos de denuncia por infracción de derechos de propiedad intelectual $;^{1}$ todo ello debido al escaso conocimiento que existe sobre sus fundamentos, requisitos y efectos jurídicos.

La parodia es una figura propia de las artes y la literatura ${ }^{2}$ que ha sido estudiada por el Derecho debido a que, por su naturaleza de crítica

* Profesora auxiliar del Departamento Académico de la Facultad de Derecho de la Pontificia Universidad Católica del Perú.

** Profesor auxiliar del Departamento Académico de la Facultad de Derecho de la Pontificia Universidad Católica del Perú.

1 Como ejemplo podemos citar el procedimiento de oficio seguido por la Oficina de Derechos de Autor del Instituto Nacional de Defensa de la Competencia y de la Protección de la Propiedad Intelectual (INDECOPI) contra la empresa Creativity Publicidad S.A., la cual realizó una parodia publicitaria de la obra "Autorretrato" del pintor Vincent Van Gogh. La autoridad administrativa sancionó a la empresa en cuestión por considerar que vulneró los derechos morales de paternidad y de integridad del pintor holandés, sin analizar el caso a la luz del artículo 48 de la Ley Peruana de Derechos de Autor que regula el tema de la parodia. Este caso será retomado más adelante.

2 Etimológicamente 'parodia' deriva de los términos 'parôidos' o 'parôidia', que a su vez derivan del vocablo 'para', que significa 'cerca' y del vocablo 'odê', que significa 
humorística de trabajos artísticos, situaciones o personajes, se ha considerado una forma de crítica social, literaria o artística relevante y, por ello, una manifestación de la libertad de expresión.

Como veremos, dentro del campo del derecho de autor, el tema de la parodia, como fenómeno jurídicamente relevante, ha tenido mayor desarrollo tanto en la doctrina como en la jurisprudencia. No obstante, debe tenerse en cuenta que - en tanto representación humorística de una situación o personaje que puede implicar una manifestación de la libertad de expresión - la parodia puede llegar a ser relevante también en otras áreas del derecho, como el derecho constitucional, principalmente debido a su posible colisión con los derechos al honor, a la intimidad o a la voz e imagen propias.

Este artículo se circunscribe al análisis de la parodia en el derecho de propiedad intelectual (específicamente referido al derecho de autor y al derecho de marcas), principalmente a partir del estudio de casos de conflicto producidos en la publicidad comercial. ${ }^{3}$

En la medida que este trabajo busca proponer los posibles elementos a tomar en cuenta para resolver los conflictos suscitados entre parodistas y titulares de derechos de propiedad intelectual, deberá considerarse la compleja naturaleza de la parodia como elemento de crítica humorística y eventual manifestación de la libertad de expresión. Esto precisamente justifica su reconocimiento como posible límite de los derechos de propiedad intelectual.

'canción', respectivamente. Según algunos autores, la palabra parodia habría sido utilizada en Grecia para referirse a ciertas creaciones artísticas en las que los temas heroicos eran objeto de mofa o involucraban citas cómicas e imitación (Véase GREDLEY, Ellen y Spyros Maniatis. "Parody: A Fatal Attraction? Part I: The Nature of Parody and its Treatment in Copyright". EIPR, n. ${ }^{\circ}$ 7, 1997, p. 339).

3 Sobre la definición de publicidad comercial, la Sala de Defensa de la Competencia del Tribunal del INDECOPI ha señalado, por medio del precedente de observancia obligatoria contenido en la resolución 096-96-TPI-SDC de fecha 11 de diciembre de 1996, lo siguiente: "Para efectos de lo dispuesto en el Decreto Legislativo No. 691 y sus normas reglamentarias, constituye publicidad comercial cualquier forma de comunicación pública que tenga por finalidad o como efecto fomentar, directa o indirectamente, la adquisición de bienes o la contratación de servicios, captando o desviando, las preferencias de los consumidores. No constituye publicidad comercial la propaganda política y la publicidad institucional, entendida esta última como aquella que tiene por finalidad promover conductas de relevancia social, tales como el ahorro de energía eléctrica, la preservación del medio ambiente, el pago de impuestos, entre otras». Resulta ilustrativo también lo dispuesto por la Ley General de Publicidad 34/1998 española, la cual define el término publicidad como «toda forma de comunicación realizada por una persona física o jurídica, pública o privada, en el ejercicio de una actividad comercial, industrial, artesanal o profesional, con el fin de promover de forma directa o indirecta la contratación de bienes muebles o inmuebles, servicios, derechos y obligaciones". 


\section{La parodia en el derecho de propiedad intelectual: una aproximación a partir del caso «autorretrato de Van Gogh"}

Una de las disposiciones que mayor polémica ha causado es aquella que regula la parodia de obras. En efecto, el artículo 49 - correspondiente al título "De los Límites al Derecho de Explotación y de su Duración" - de la Ley peruana de Derechos de Autor ${ }^{4}$ señala que «no será considerada transformación que exija autorización del autor la parodia de una obra divulgada mientras no implique riesgo de confusión con la misma ni se infiera un daño a la obra original o a su autor y sin perjuicio de la remuneración que le corresponda por esa utilización».

El primer problema que presenta nuestra ley es que no define lo que debemos entender por parodia, motivo por el cual es necesario acudir a las definiciones dadas por la doctrina. Así, la parodia ha sido definida como:

[...] toda reelaboración de una obra seria —narrativa, poética o de teatro-, la cual, conservando manifiestamente la configuración externa, de argumento y desarrollo, de la obra original, invierte las situaciones y los efectos, de modo que se provoque la risa en lugar del llanto, y aprovecha a tal fin no tanto una propia vis cómica autónoma como la continua correspondencia risible de los singulares personajes y momentos joviales de esa parodia comparados con los recíprocos y contrarios de la obra original. $^{5}$

Y también ha sido definida como «una imitación burlesca de una obra seria. Se trata de una obra derivada, original en la composición y en la expresión». ${ }^{6}$ En consecuencia, para que podamos hablar de una parodia, debemos estar, en principio, frente a una manifestación festiva, cómica, ridícula o jocosa, basada en una obra protegida por el Derecho de Autor. ${ }^{7}$

En los Estados Unidos de Norteamérica, la jurisprudencia sobre copyrig$h t$ ha recogido las definiciones literarias tradicionales de la parodia y la ha distinguido claramente de otros recursos humorísticos como la sátira. En el

4 Decreto Legislativo 822, publicado en el diario oficial El Peruano el 24 de abril de 1996.

5 Diaz Alabart recoge la definición de Musatti ("La Parodia e II Diritto d'Autore"), en Díaz ALABART, Silvia. "Comentario al artículo $39 \mathrm{LPI}$. En Rodrigo Bercovitz Rodríguez-Cano (coord.). Comentarios a la Ley de Propiedad Intelectual. Madrid: Tecnos, 1997, p. 663664.

- LIPSZYC, Delia. Derechos de autor y derechos conexos. París: UNESCO, 1993, p. 118.

- Cabe señalar que el efecto ridículo de la parodia no es considerado un requisito indispensable por parte de toda la doctrina. Así, algunos autores sostienen que puede existir parodia también en el caso de imitaciones humorísticas hechas con admiración o reverencia y no con la intención de ridiculizar el trabajo parodiado (GREDLEY y MANIATIS, op. cit., p. 340). 
caso Campbell v. Acuff-Rose $(1994)^{8}$ la Corte Suprema de los Estados Unidos analizó, por primera vez, a la parodia como un supuesto de uso lícito de un trabajo protegido por el copyright y, además, estableció una importante diferencia entre parodia (cuyo blanco de burla es un trabajo protegido por el copyright, al cual imita) y sátira (que eventualmente, pero no necesariamente, puede referirse o utilizar partes de un trabajo protegido por el copyright como vehículo para burlarse de otro blanco u objetivo). ${ }^{9}$

La protección jurídica de la parodia en el sistema legal norteamericano está determinada por su inclusión dentro de alguno de los supuestos de uso lícito u honrado (fair use) de un trabajo protegido por el copyright. De acuerdo a la doctrina del fair use, existen ciertos usos de las obras o trabajos protegidos por el copyright que se consideran libres, es decir, que no requieren la previa autorización del autor ni el pago de una remuneración a este, en la medida en que buscan satisfacer intereses socialmente relevantes, de índole cultural, informativo o didáctico. ${ }^{10} \mathrm{El}$ caso de la parodia es entonces una forma de uso libre, pues está dentro de la excepción de uso por razón de propósitos críticos o de comentario ("for purposes such as criticism, comment») del trabajo protegido por el copyright.

En la medida en que la parodia es protegida como un tipo de fair use, en tanto comentario o crítica del trabajo original, la Corte Suprema

8 En este caso, la Corte Suprema de los Estados Unidos no desarrolló una definición propia de parodia y, más bien, se remitió a la definición dada por el American Heritage Dictionary («literary or artistic work that imitates the characteristic style of an author or a work for comic effect or ridicule») y el Oxford English Dictionary («composition in prose or verse in which the characteristic turns of thought and phrase in an author or class of authors are imitated in such a way as to make them appear ridiculous") [Campbell v. Acuff-Rose Music, Inc. Apartado II, A. (<http://laws.findlaw.com/US/000/ u10426.html>)].

9 Por ello, la Corte sostiene que: «Parody needs to mimic an original to make its point, and so has some claim to use the creation of its victim's (or collective victims') imagination, whereas satire can stand on its own two feet and so requires justification for the very act of borrowing" [Campbell v. Acuff-Rose Music, Inc. Apartado II, A. (<http:// laws.findlaw.com/US/000/u10426.html>)].

10 Según la Sección 107 del Copyright Act de 1976: "Notwithstanding the provisions of sections 106 and 106A, the fair use of a copyrighted work, including such use by reproduction in copies or phonorecords or by any other means specified by that section, for purposes such as criticism, comment, news reporting, teaching (including multiple copies for classroom use), scholarship, or research, is not an infringement of copyright. In determining whether the use made of a work in any particular case is a fair use the factors to be considered shall include - (1) the purpose and character of the use, including whether such use is of a commercial nature or is for nonprofit educational purposes; (2) the nature of the copyrighted work; (3) the amount and substantiality of the portion used in relation to the copyrighted work as a whole; and (4) the effect of the use upon the potential market for or value of the copyrighted work. The fact that a work is unpublished shall not itself bar a finding of fair use if such finding is made upon consideration of all the above factors". 
norteamericana ha considerado que la parodia que se burla o ridiculiza costumbres o valores sociales contemporáneos, pero cuyo objeto de crítica no es el trabajo protegido por el copyright, no es, en estricto, una parodia, sino más bien una sátira. La Corte entiende que a esta no se le debe otorgar la protección del fair use, pues para lograr su objetivo de crítica o comentario social no requiere del necesario uso del trabajo original. En cambio, la parodia, que de algún modo crítica o comenta un trabajo preexistente (una canción, una película o una obra literaria, por ejemplo), necesariamente requiere utilizar partes de dicho trabajo a fin de evocarlo en la mente del receptor, pues no existe parodia donde nadie reconozca el trabajo parodiado. Por ello, solo a este tipo de crítica (parodia de una obra protegida por el copyright) se le otorga la protección del fair use. ${ }^{11}$

La justificación de la parodia, entonces, está en su naturaleza de crítica literaria o artística del trabajo protegido por el copyright. En ese sentido, el fundamento del fair use no debe ser confundido con el fundamento de la libertad de expresión, reconocida en los Estados Unidos en la Primera Enmienda de su Constitución. ${ }^{12}$ Esto quiere decir que la parodia no se considera protegida simplemente por el hecho de constituir una forma de expresión. Para la Corte Suprema, deber ser, siempre, una expresión crítica sobre el trabajo original.

La jurisprudencia norteamericana ha sostenido, de forma reiterada, que no puede alegarse la Primera Enmienda como una excepción a los derechos

" Cabe señalar que en los casos en que se invoca la protección del fair use es necesario, conforme lo establece la propia Copyright Act, analizar cuatro factores determinantes:

1) El propósito y las características del uso (en el caso que nos ocupa, d? una parodia). De este modo, se deberá establecer si, por ejemplo, estamos ante una copia servil o, más bien, ante una transformación del trabajo original, o si se trata de un uso de naturaleza comercial o de tipo cultural no lucrativo.

2) La naturaleza del trabajo protegido por el copyright. Aquí se analiza, por ejemplo, su mayor o menor grado de originalidad, lo cual determina una mayor o menor protección.

3) La cantidad y calidad de la porción usada del trabajo protegido por el copyright. Se pregunta cuánto del trabajo original puede ser utilizado por el nuevo uso de forma lícita a fin de lograr su objetivo (en el caso de la parodia, por ejemplo, para lograr evocar en la mente del público el trabajo que se parodia).

4) El efecto del uso del material protegido (parodia, por ejemplo) en el mercado potencial o en el valor del trabajo protegido. Se trata de advertir si el nuevo uso pretende sustituir al trabajo original compitiendo con él en su mismo mercado, por ejemplo.

12 La Primera Enmienda de la Constitución de los Estados Unidos establece lo siguiente: "Congress shall make no law respecting an establishment of religion, or prohibiting the free exercise thereof; or abridging the freedom of speech, or of the press; or the right of the people peaceably to assemble, and to petition the Government for a redress of grievances" [CONGRESSIONAL RESEARCH SERVICE LIBRARY OF CONGRESS, The Constitution of the United States of America. Analysis and Interpretation, 2000 (<http:// www.access.gpo.gov/congress/senate/costitution/toc.html >), p. 969]. 
de propiedad intelectual y a la protección conferida por el copyright. Así, ha señalado que la protección otorgada a la libertad de expresión mediante la Primera Enmienda ha sido adecuadamente canalizada a través de la figura del fair use - que autoriza los comentarios críticos del trabajo original y está reconocida en la ley de copyright $-{ }^{13}$ y también mediante la denominada tesis de la dicotomía entre idea y expresión. ${ }^{14}$

Algunos autores ${ }^{15}$ consideran, sin embargo, que es posible invocar la Primera Enmienda (libertad de expresión) como medio de defensa de la

13 Véase Suntrust v. Houghton Mifflin (2001), donde el Décimo Primer Circuito de la Corte de Apelaciones de los Estados Unidos ha señalado que: "Because of the First Amendment principles built into copyright law through the idea/expression dichotomy and the doctrine of fair use, courts often need not entertain related First Amendment arguments in a copyright case. See, e.g. [...] Nihon Keizai Shimbun, Inc. v. Comline Bus. Data, Inc., 166 F. 3d 65, 74 (2d Cir. 1999) ( $(W e$ have repeatedly rejected First Amendment challenges to injunctions from copyright infringement on the ground that First Amendment concerns are protected by and coextensive with the fair use doctrine".); Los Angeles News Serv. V. Tullo, 973 F. 2d 791, 795 (9th Cir. 1992) («First Amendment concerns are also addressed in the copyright field through the 'fair use' doctrine»)». (http://laws.findlaw.com/11th/ $0112200 \mathrm{opn} . \mathrm{html}$ ).

14 La tesis de la dicotomía entre idea y expresión sostiene que el Derecho de Propiedad Intelectual (Derecho de Autor o copyright) solo protege la forma de expresión de una idea, más no la idea misma. En la medida que el Derecho de Autor reconoce una suerte de propiedad exclusiva al creador de una obra, esta no puede referirse a simples ideas, pues esto supondría establecer un derecho exclusivo sobre las ideas y limitar, de este modo, el libre intercambio de las mismas, y con ello la libertad de expresión. El derecho de autor, por eso, únicamente protege la forma en que se plasma una idea; así por ejemplo, la forma en que una historia de amor es narrada por el escritor o plasmada en una película por un director cinematográfico, pero no la historia misma. Esta regla ha llevado a la jurisprudencia norteamericana a afirmar que, en virtud de ella (y del aludido recurso del fair use), existe una garantía plena de la libertad de expresión en las normas del copyright, y ha llevado a negar todo posible conflicto con el derecho a la libertad de expresión. Así, en el caso Harper \& Row v. Nation Enterprises (1985), la Corte Suprema de los Estados Unidos estableció que: "The Second Circuit noted, correctly, that copyright's idea/expression dichotomy «strike[s] a definitional balance between the First Amendment and the Copyright Act by permitting free communication of facts while still protecting an author's expression." 723 F. 2d, at 203. No author may copyright his ideas or the facts he narrates. 17 U.S.C 102 (b). See, e.g., New York Times Co. v. United States, 403 U.S. 713, 726, n (1971) (BRENNAN. J., concurring) (Copyright laws are not restrictions on freedom of speech as copyright protects only form of expression and not the ideas expressed); Nimmer 1.10[B]2. As this Court long ago observed: "[T] element - the information respecting current event contained in the literary productionis not the creation of the writer, but is a report of matters that ordinarily are publicijuris: it is the history of the day». International News Service v. Associated Press, 248 U.S. 215, 234 (1918). But copyright assures those who write and publish factual narratives such as "A Time to Heal" that $[\ldots]$ they may at least enjoy the right to market the original expression contained therein as just compensation for their investment. Cf. Zacchini v. Scripps-Howard Broadcasting Co., 433 U.S. 562, 575 (1977)". (<http://laws.findlaw.com/ us/471/539.html >).

15 Véase, Shauchnessy, Robert. «Trademark Parody: A Fair Use and First Amendment Analysis". The Trademark Reporter, vol. 77, n. ${ }^{\circ}$ 3, mayo-junio, 1987, pp. 204- 209. 
parodia en el campo del copyright (al igual que en el caso de las parodias de marcas), independientemente del hecho de que esta pueda constituir o no una crítica del trabajo (protegido por el copyright) que está siendo parodiado. Ello sería posible en la medida que se demuestre que, en un caso concreto, se presenta una necesaria unión entre la idea que se quiere transmitir y la expresión que se utiliza para ello (en este caso, la parodia). Esta propuesta es conocida como la tesis de la unión idea-expresión. Bajo esta óptica, la parodia sería lícita, aun sin constituir una crítica del trabajo original que se parodia, cuando no exista otra forma, más allá de esa específica parodia, de expresar una determinada idea. Este argumento supone establecer un necesario equilibrio entre el copyright y la Primera Enmienda. ${ }^{16}$

Hasta el momento, la Corte Suprema de los Estados Unidos no ha aceptado la tesis de la unión idea-expresión como mecanismo de defensa en los casos de parodias de obras protegidas por el copyright. No obstante, sus fundamentos teóricos han sido desarrollados en algunos casos por los tribunales, y aunque no ha servido para resolverlos, esta tesis podría ser aceptada en futuros casos en los que se deba decidir con respecto a la licitud de una parodia.

En el caso Walt Disney Productions v. Air Pirates (1978), por ejemplo, el Noveno Circuito de la Corte de Apelaciones reconoció la posibilidad de establecer una defensa de la parodia por medio de la Primera Enmienda, aunque rechazó su aplicación en el caso concreto. La Corte sostuvo que, en efecto, existía una tensión entre la Primera Enmienda y el Copyright Act, y que la tesis de la dicotomía entre idea-expresión representaba una posibilidad de ponderación (definitional balance) entre el copyright y los intereses del free speech. Sin embargo, determinó que, en el caso en cuestión, los demandados no podían recurrir a dicha tesis, ya que pudieron haber expresado su idea sin necesidad de copiar la expresión protegida de Walt Disney (se trataba de un comic underground que reproducía conocidos personajes de Disney, como Mickey Mouse, en situaciones de promiscuidad, consumo de drogas y demás circunstancias antisociales). ${ }^{17}$

En el caso Harper \& Row Publisher v. Nation Enterprises (1980) también se alegó una defensa basada en la Primera Enmienda, pero fue rechazada por la

16 Aunque el Copyright Act no constituye una norma de rango constitucional, puede remitirse al artículo l, sección 8 de la Constitución norteamericana, que establece lo siguiente: "The Congress shall have power [...] to promote the Progress of Science and useful Arts, by securing for limited Times to Authors and Inventors the exclusive Rights to their respective Writings and Discoveries". De este modo, el balance entre copyright y Primera Enmienda se traduce en un equilibrio entre normas constitucionales e intereses constitucionalmente reconocidos.

17 Walt Disney Productions v. Air Pirates. Apartado I C. (<http://ww.lawstudents.org/copyright/cases/581F2D751.html>). 
Corte Suprema que, sin embargo, no descartó la posibilidad de que fuese utilizada como argumento de defensa en otros casos de copyright. En el caso, la revista The Nation usó en un artículo varias citas textuales de las memorias no publicadas del ex presidente de los Estados Unidos Gerald Ford. La revista sostuvo que el uso de dichas citas - no solo los hechos ahí narrados sino la forma en que eran narrados - era imprescindible para la transmisión de las ideas que se querían exponer en el artículo, que estaba referido a un tema de interés público y que, por lo tanto, estaba protegido por la Primera Enmienda. La Corte, por su parte, consideró que ningún autor podía alegar un derecho de copyright sobre las ideas o hechos narrados por él. Así, señaló que «las leyes del Copyright no son restricciones al freedom of speech ya que el Copyright sólo protege las formas de expresión y no las ideas expresadas». ${ }^{18}$ En el caso, sin embargo, sostuvo que las porciones tomadas del manuscrito de Gerald Ford habían sido excesivas, y rechazó el argumento de defensa basado en la Primera Enmienda porque las citas en cuestión no eran esenciales para narrar los hechos de relevancia pública (no existía la necesaria unión entre idea y expresión).

Cabe señalar que la Primera Enmienda y la tesis de la unión idea-expresión del copyright también podría servir para proteger las parodias de marcas. Debido a la ausencia de una figura legal como la del fair use en el campo del derecho de marcas, ${ }^{19}$ autores como Robert Shaughnessy consideran que los tribunales deberían ser más tolerantes con los argumentos de defensa basados en la Primera Enmienda, en los casos de parodias de marcas. ${ }^{20}$

Shaughnessy considera incluso que la protección que se confiere a la parodia mediante la tesis de la unión idea-expresión es demasiado restrictiva, ya que, aunque en ciertos casos es posible que el parodista pueda expresar su idea sin necesidad de utilizar una marca determinada, la elección de dicho medio de expresión refleja una forma de expresarse que, en sí misma, ya debe ser protegida. En algunas ocasiones, una expresión (como la parodia) puede no ser la única forma de transmitir una idea y, sin embargo, debería ser

is Harper \& Row v. Nation Enterprises (1985), Fundamento III, B.

19 Actualmente la licitud de la parodia de una marca en los Estados Unidos depende del cumplimiento de varios requisitos. En primer lugar, a partir del caso Campbell $v$. AcuffRose - que aunque es un caso de copyright constituye un leading case cuya doctrina es aplicable a todos los supuestos de parodia dentro del campo de la propiedad intelectual - la parodia debe constituir una crítica del trabajo original (en este caso, de la marca parodiada). Luego, la parodia deberá someterse al test de riesgo de confusión establecido por el Lanham Act para todos los supuestos de uso no autorizado de una marca y, eventualmente, al test de riesgo de dilución de la marca. De este modo, la protección de una marca frente a una parodia es más reforzada que en el caso del copyright.

2o ShAughNESSY, op. cit., p. 210. 
protegida al ser una forma de expresión elegida por el sujeto. Cada forma de expresión del sujeto es única en cierta forma y es, como la expresión misma, una manifestación de su propio $y o{ }^{21}{ }^{21}$ Por qué deberíamos entrometernos entonces en la elección que hace el sujeto de sus formas de expresión? El problema de llevar al límite este argumento es que, obviamente, podría redundar en una desprotección absoluta del propietario de la obra o de la marca protegida por el derecho de propiedad intelectual y, por ello, sería una forma de desincentivar la creación intelectual.

Citando el caso Mutual of Omaha Insurance Co. v. Novak ${ }^{22}$ (1985), Tyrone Tasker refiere que, en algunos casos, puede ser posible que el parodista transmita su idea sin usar la marca. Así, en el presente caso, el parodista pudo haber expresado sus inquietudes sobre el tema de la carrera armamentista nuclear sin usar la marca del demandante, pero esta le permitió transmitir sus ideas de una manera particular. La parodia de esa marca sirvió como un poderoso medio de comunicación para que el parodista se expresara sobre un tema de interés público, que está protegido por la Primera Enmienda de la Constitución norteamericana. ${ }^{23}$

n Los fundamentos del derecho a la libertad de expresión no solo se basan en los beneficios colectivos y personales que proporciona este derecho, esto es, su contribución en el descubrimiento de la verdad (teorías epistemológicas), el fortalecimiento del sistema democrático (teorías democrático-políticas) o la autorrealización del individuo (teorías humanistas). La libertad de expresión se protege, también, más allá de sus efectos o consecuencias, porque constituye una emanación de la dignidad del sujeto. Por ello, Ronald Dworkin afirma que, cuando se restringen las formas de expresión elegidas por el sujeto, se puede llegar a vulnerar su dignidad (DWORKIN, Ronald. Los Derechos en Serio, $2 .^{a}$ ed. Barcelona: Ariel, 1989, pp. 293-302). Para un desarrollo sobre las teorías y los fundamentos de la libertad de expresión, véase: MARCIANI, Betzabé. El Derecho a la Libertad de Expresión y la Tesis de los Derechos Preferentes. Lima: Palc tra, 2004.

n En el caso, la compañía de seguros Mutual of Omaha era titular de la marca Mutual of Omaha y la figura de la cabeza de un indio. Además, era auspiciadora de un programa de televisión llamado Mutual of Omaha Wild Kingdom. El demandado, por su parte, creó una línea de productos, como gorros y polos, con el término Mutant of Omaha y la figura de la cabeza de un sujeto demacrado con un sombrero de guerra indio con las palabras "Seguro de Holocausto Nuclear" y "Reino Mutante» o "Reino Mutante del Mutante de Omahan; todo ello para criticar sarcásticamente la carrera armamentista.

s TASKER, Tyrone. "Parody or Satire as a Defense to Trademark Infringement". The Trademark Reporter, vol. 77, n. ${ }^{\circ}$, mayo-junio, pp. 205-206. En el caso, sin embargo, la Corte de Apelaciones del Octavo Circuito no se pronunció sobre una posible defensa del parodista a partir de la Primera Enmienda, y declaró ilícita la parodia, estableciendo que una marca podía ser protegida contra el ridículo (lbidem, p. 243). En un caso posterior, L.L. Bean, Inc. v. Drake Publishers, Inc. (1987), donde el demandado parodió el famoso catálogo de L.L. Bean en un reportaje titulado "L. L. Beam's Back-To-SchoolSex-Catalog», con fotografías de desnudos y sexo explícito incluidos, otro tribunal aceptó la defensa propuesta por el parodista a partir de la Primera Enmienda. Así, el Primer Circuito de la Corte de Apelación concluyó en el caso que la parodia, aunque ofensiva, era una forma de crítica social y literaria protegida por la Primera Enmienda. Además, sostuvo que el derecho que tenía el titular de la marca en cuestión no le otorgaba un 
Consideramos que la exigencia de la necesaria unión entre idea y expresión, como única posibilidad de defensa a partir del derecho a la libertad de expresión reconocido por la Primera Enmienda, constituye un requisito demasiado gravoso para el parodista y va contra el espíritu de dicha norma constitucional, pues impide que el sujeto que se expresa emplee los elementos que considere más adecuados para hacerlo. De esta manera, se podría estar predeterminando - de manera negativa - las formas en que el sujeto se puede, o no, expresar. Además, implica una protección limitada de las parodias, ya que, al no cumplirse con el requisito en cuestión, la única posibilidad que le queda al parodista es ubicarse dentro del estrecho marco de protección del fair use -únicamente aplicable al caso de parodias de obras protegidas por el copyright, pero no a las parodias de marcas- que, como vimos, desde una perspectiva limitada de lo que significa la parodia, exige que esta constituya una crítica del trabajo original protegido por el copyright. Esto, en los hechos, puede llevar a apreciaciones demasiado subjetivas por parte de los jueces, quienes están llamados a «descubrir» las supuestas críticas que el parodista quiso hacer al trabajo original, cuando lo más probable es que ni siquiera fueran imaginadas o tomadas en cuenta por este al momento de realizar la parodia.

Es cierto que, en algunos casos, es posible advertir una manifiesta crítica del trabajo parodiado, como ocurrió en el caso Campbell v. Acuff-Rose (se trataba de una versión en rap de la conocida canción "Pretty Woman"; como seńaló la Primera Instancia, por medio de la parodia se pretendía mostrar la banalidad de la canción original). ${ }^{24}$ Sin embargo, en muchos casos dicha crítica no es tan evidente y, como dijimos, a veces resulta casi una construcción artificial de los jueces que pretenden, de este modo, hacer encajar el supuesto de la realidad en la categoría de parodia protegida por el fair use. Esto redunda en una peligrosa situación de inseguridad jurídica, en la medida en que la determinación de la naturaleza crítica de la parodia

escudo que le permitiera aislarse de la crítica y de los comentarios no favorables a su marca (Shaughnessy, op. cit., pp. 213-215; KelleR, Bruce y David BERNSTEIN. "As Satiric As They Wanna Be: Parody Lawsuits Under Copyright, Trademark, Dilution and Publicity Laws». The Trademark Reporter, vol. 85, pp. 252-253).

24 En un caso más reciente, Lyons Partnership v. Ted Ciannoulas (1999), el propietario del conocido muñeco Barney entabló una demanda contra el titular de los derechos de propiedad intelectual de la mascota deportiva conocida como "The Famous Chicken", debido a las apariciones de esta última en diversos eventos deportivos junto a un muñeco que representaba un dragón, llamado "Duffy", el cual era una parodia de Barney. En dichos eventos, el Dragón Duffy era objeto de burla por parte de The Famous Chicken a causa de su torpeza e inocencia. En el caso, el Quinto Circuito de la Corte de Apelaciones consideró que existía una clara crítica a las actitudes del muñeco Barney (parodiado mediante el muñeco Duffy) y, por ello, una parodia que debía ser protegida conforme a lo establecido en el caso Campbell $v$. Acuff-Rose. 
respecto del trabajo parodiado termina quedando en manos de la subjetiva apreciación de los tribunales. Así por ejemplo, en el caso Leibovitz v. Paramount Pictures (1998), ${ }^{25}$ el Segundo Circuito de la Corte de Apelaciones consideró que la parodia de la fotografía de la actriz Demi Moore podía percibirse como un comentario crítico sobre la seriedad y el carácter pretencioso del trabajo original (la fotografía en cuestión), o también, como un comentario crítico o una forma de desacuerdo con la idea que pretendía transmitir dicha obra (la belleza del cuerpo de una mujer embarazada). Lo más probable es que toda esa construcción crítica no estuviera en la mente de los creadores de dicha parodia cuando la realizaron y que, más bien, hayan pensado que esa era una forma ingeniosa y jocosa de promocionar su nueva película cómica. La obra original y la parodia en cuestión son las siguientes:
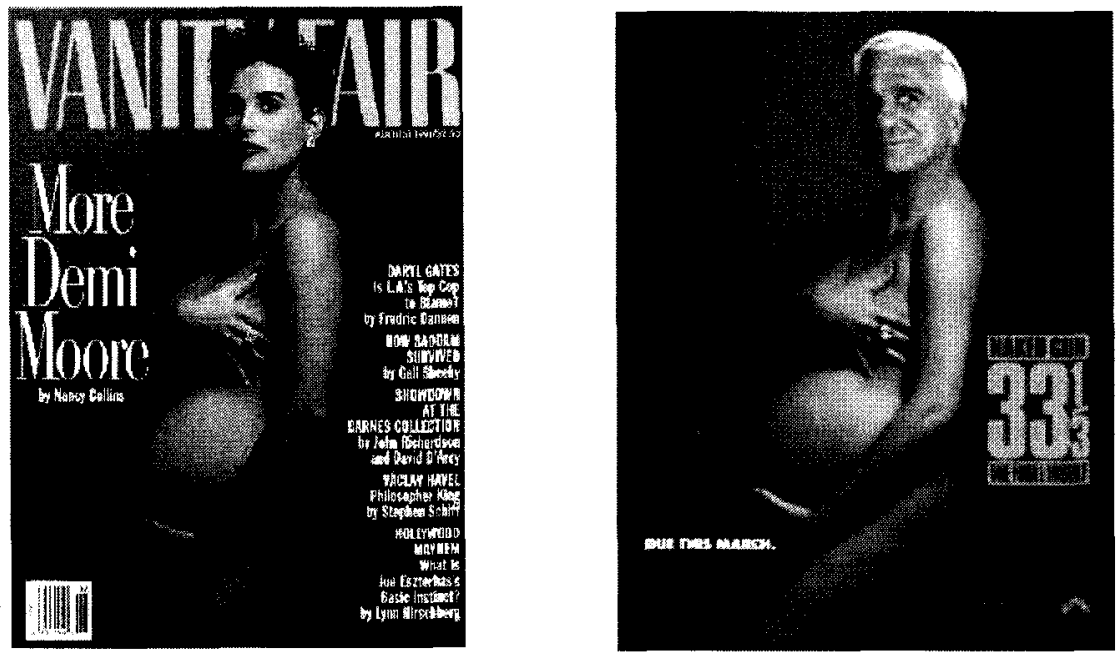

A diferencia del caso citado, en un caso más antiguo pero que resulta ilustrativo [Original Appalachian Artworks, Inc. v. Topps Chewing Gum, Inc. (1986)], otro tribunal consideró que la parodia de los muñecos «Cabbage Patch Kids», hecha por el demandado mediante unas calcomanías en las que aparecían esos dulces muñecos en imágenes sádicas o desagradables y a

55 En 1991, la revista Vanity fair publicó en su carátula la fotografía de la actriz Demi Moore, desnuda y embarazada (la autora fue la afamada fotógrafa Annie Leibovitz). En 1993 Paramount Pictures lanzó una campaña publicitaria para la película Naked Gun 33 1/3: The Final Insult, donde aparecía el rostro del actor cómico Leslie Neilsen impuesto sobre el cuerpo de una mujer desnuda y embarazada, en una pose y fondo bastante similar a la fotografía de Leibovitz. Frente a la denuncia de la fotógrafa, Paramount Pictures señaló en su defensa que, en virtud del fair use, había realizado una parodia lícita. El Segundo Circuito de la Corte de Apelación de Estados Unidos le dio la razón a la productora cinematográfica. 
quienes llamaron "Garbage Pail Kids", no constituía una parodia en sentido estricto pues no existía una clara intención de criticar el original, sino más bien de hacer dinero. El muñeco original y una de sus parodias son las siguientes:
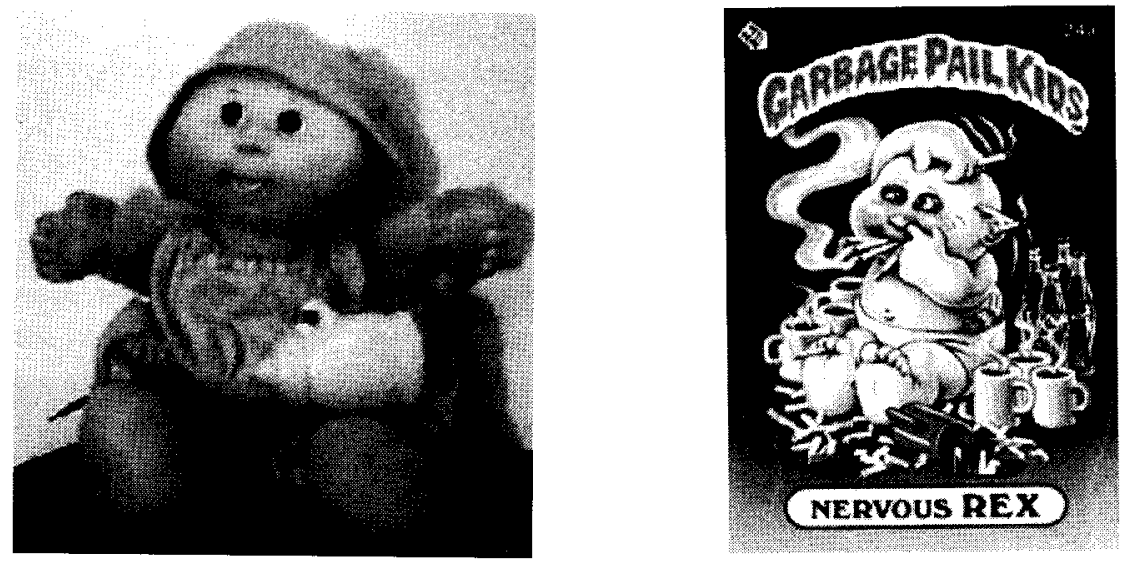

Las interrogantes que aparecen entonces son: ¿Cuál es la gran diferencia que existe entre el caso Leibovitz y este último? ¿Quién puede determinar, en última instancia, cuándo existe o no una crítica del trabajo original? ¿Acaso en el caso Original Appalachian Artworks, Inc. no podríamos sostener que existe una implícita crítica del carácter tierno y dulce de los muñecos parodiados?

Es importante notar que en el tratamiento que se da a la parodia en la Ley peruana de Derechos de Autor no se alude a la necesidad de crítica de la obra original, a diferencia del caso de la jurisprudencia norteamericana. Consideramos que esta opción es adecuada, en la medida en que entendemos que la parodia, más allá de constituir una forma de crítica del material protegido es, o puede llegar a ser, una manifestación de la libertad de expresión del parodista. Desde esa perspectiva, y sin desconocer el derecho de propiedad intelectual, que tiene base constitucional, es un acierto prescindir de tal requisito, más aún cuando la ley se ha cuidado de establecer otros requisitos que sí son importantes y adecuados - a excepción del requisito de la remuneración que cuestionaremos más adelante-, como la necesidad de que la obra original parodiada haya sido previamente divulgada, que la parodia no produzca riesgo de confusión con el trabajo original y que no infiera daño a este o a su autor.

Lamentablemente, hasta la fecha no hay pronunciamiento alguno por parte del INDECOPI relacionado con el tema de la parodia. Sin embargo, es digno de citar un famoso caso que pudo haberse analizado utilizando los alcances del mencionado artículo 49. Nos estamos refiriendo al procedi- 
miento de oficio iniciado el 1 de marzo de 1999 por la Oficina de Derechos de Autor contra Creativity Publicidad S.A. ${ }^{26}$ el cual procederemos a reseñar brevemente.

Los días 22, 23 y 26 de febrero de 1999 Creativity Publicidad S.A. publicó en la sección A del diario El Comercio un anuncio publicitario donde se parodiaba la obra «Autorretrato» del pintor Vincent Van Gogh. Cabe resaltar que dicho anuncio presentaba dos reproducciones alteradas de la pintura del autor holandés: la primera mostraba la obra de manera borrosa, mientras que la segunda mostraba la obra completa a la que se le añadía una mano izquierda sosteniendo un teléfono celular. Asimismo, en dicho anuncio no se mencionaba al autor de la obra y se habían omitido todos los colores de esta. La obra original ${ }^{27}$ y su parodia publicitaria son las siguientes:
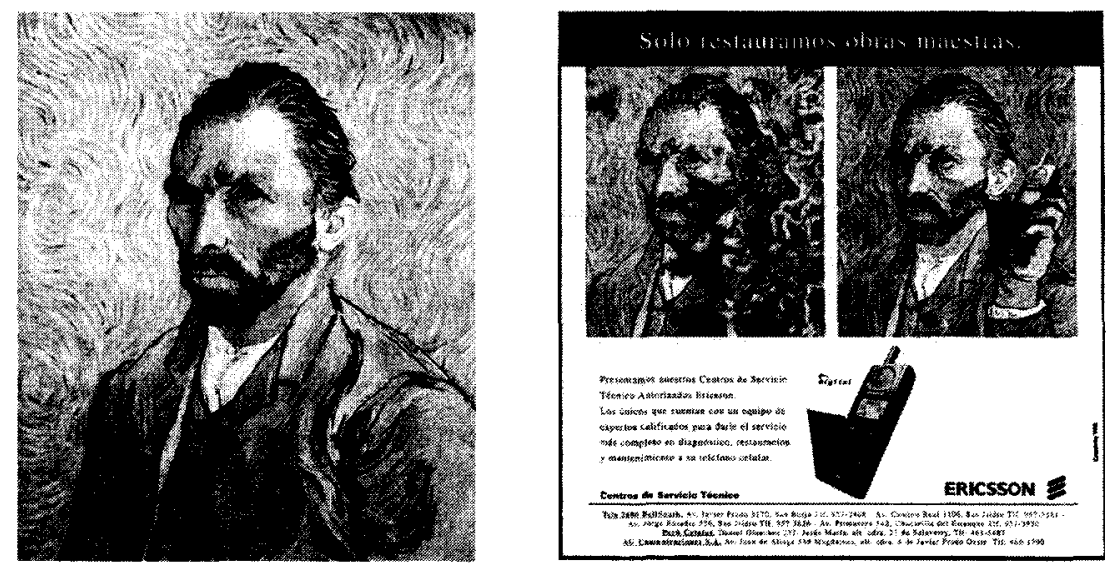

El 8 de marzo de 1999, Creativity Publicidad S.A. señaló en su descargo la existencia de diversas piezas publicitarias a nivel nacional e internacional donde se utilizan obras de arte universal modificadas para comunicar con ingenio un concepto o mensaje determinado. El 29 de marzo de 1999, se realizó la audiencia de conciliación, en la cual la Oficina de Derechos de Autor propuso como fórmula conciliatoria la publicación en el mismo diario, a costa de la denunciada, de un aviso señalando que las obras literarias $y$ artísticas deben respetarse y que por lo tanto no se puede alterar su integridad, aún cuando estas hayan pasado a dominio público. El representante de la empresa denunciada no estuvo de acuerdo y se retiró sin firmar el

26 Expediente 228-1999-ODA-INDECOPI.

v Beaujean, Dieter. Vincent van Vogh. Vida y obra. Colonia: Könemann, 2000, p. 78. 
acta correspondiente. En consecuencia, el 7 de mayo de 1999 la Oficina de Derechos de Autor emitió la resolución 097-1999-ODA, declarando fundada la denuncia de oficio seguida contra Creativity Publicidad S.A. por infracción a los derechos morales de Vincent Van Gogh — derecho de paternidad (ya que se omitió colocar el nombre del autor de la obra original) y de integridad (ya que se modificó la obra original) - , sancionando a la empresa con una Unidad Impositiva Tributaria y ordenando la publicación de dicha resolución en el diario oficial El Peruano.

Aunque el caso es discutible, estamos de acuerdo con la Oficina de Derechos de Autor respecto a la existencia de una vulneración al derecho moral de paternidad del autor. Sin embargo, consideramos que el caso debió analizarse, también, a la luz del artículo 49, referido al tema de la parodia, a fin de evaluar mejor la supuesta vulneración del derecho moral de integridad.

Analizaremos a continuación los cuatro requisitos que establece la norma para que una parodia sea considerada lícita, apoyándonos en el caso "Autorretrato de Van Gogh».

\subsection{La obra parodiada debe encontrarse divulgada}

Según el numeral 9 del artículo 2 de la Ley de Derechos de Autor, la divulgación implica «hacer accesible la obra, interpretación o producción al público por primera vez con el consentimiento del autor, el artista o el productor, según el caso, por cualquier medio o procedimiento conocido o por conocersem. En consecuencia, sería ilícita la parodia de una obra cuyo autor haya decidido que permanezca inédita en uso de su derecho moral de divulgación.

La obra de Van Gogh fue divulgada con su consentimiento, de manera tal que en el caso en cuestión se cumple con el primer requisito.

\subsection{La parodia y la obra parodiada no deben causar confusión entre sí}

Es importante apreciar que este es un requisito que se presenta también en el tratamiento de la parodia en los Estados Unidos. La justificación de dicho requisito descansa en la necesidad de proteger tanto al titular del derecho de autor, como al consumidor.

De este modo, se busca evitar que con el pretexto de la parodia se produzca, en los hechos, una copia servil del trabajo original que redunde en un aprovechamiento indebido del esfuerzo ajeno. La idea es que el nuevo trabajo producido (la parodia) no pretenda sustituir a la obra original en el mercado. Además, se tutela el derecho que tiene el consumi- 
dor a recibir información adecuada sobre las obras protegidas por el derecho de autor a que tiene acceso. En esa medida, por ejemplo, la Corte Suprema de los Estados Unidos ha considerado que la remisión a la obra original debe ser la necesaria para evocar en la mente del público el trabajo original parodiado. ${ }^{28}$

En el caso analizado, advertimos que ambas obras deben estar en perfecta capacidad de ser diferenciadas entre sí por parte del público. En efecto, la parodia debe implicar una modificación que se perciba como cómica o jocosa. Sobre el particular, Silvia Díaz Alabart señala que «el elemento diferenciador por excelencia, señalado por todos los autores, es que en la parodia se da un cambio de lo que es serio en la obra originaria parodiada a cómico". ${ }^{29}$

Si analizamos con cuidado la parodia publicitaria de la obra de Van Gogh, advertiremos que aparecen dos reproducciones alteradas de la pintura denominada "Autorretrato». La del lado derecho, donde aparece el pintor sosteniendo un teléfono celular, resulta jocosa y no consideramos que pueda causar confusión con la obra original, lo cual no sucede con la figura del lado izquierdo, pues al aparecer deteriorada y borrosa podría generar en el público la idea de que la obra original se encuentra en dicho estado.

Asimismo, el anuncio publicitario menciona en letras grandes: «Sólo restauramos obras maestras", presentando a continuación ambas figuras. Esto reforzaría la tesis de que algunas personas podrían pensar que el original de la obra maestra de Van Gogh se encuentra actualmente deteriorado y necesita algún tipo de restauración.

\subsection{La parodia no debe causar daño a la obra original ni a su autor}

Este requisito se encuentra estrechamente ligado a los derechos morales de los autores, los cuales son perpetuos, inalienables, inembargables, irrenunciables e imprescriptibles. A pesar del fallecimiento del autor y aunque su obra haya pasado a dominio público, este pervive por intermedio de su creación y conserva incólume su derecho a que la obra se mantenga conforme fue elaborada. Asimismo, conforme señalan Carlos Villalba y Delia Lipszyc, "el público tiene derecho a conocer expresiones creativas genuinas, no bastardeadas". ${ }^{30}$

${ }_{28}$ Campbel/ v. Acuff-Rose Music, Inc. Apartado II, C. (<http://laws.findlaw.com/US/000/ u10426.html >).

29 DIAZ AlABART, op. cit., p. 682.

3o VILlalba, Carlos y Delia LipSzyc. El Derecho de Autor en la Argentina. Buenos Aires: La Ley, 2001, p. 90. 
En tal sentido, la parodia no puede suponer una vulneración al honor o a la dignidad del autor ni mucho menos dañar la obra parodiada. La obra original y su autor solo pueden tolerar un uso cómico que no llegue a causar daño. Al respecto, Germán Bercovitz indica que «la intención humorística no podrá servir de escudo para aquellos que lo que objetiva y realmente pretendan sea herir la sensibilidad del autor [...]». ${ }^{31} \mathrm{El}$ argumento anterior debe, sin embargo, valorarse en concordancia con otros intereses y bienes jurídicos relevantes, tales como el derecho a la libertad de expresión y los principios de tolerancia y pluralismo, propios de un sistema democrático.

Como resulta evidente, la parodia casi siempre implica un daño a la obra original ( $\mathrm{y}$ a su autor) en la medida en que suele constituir una crítica mordaz de dicha obra. Siendo esto así, ¿cómo debería entenderse la referencia que hace la ley respecto al daño a la obra original en el caso de una parodia? En los Estados Unidos se ha sostenido que el daño al trabajo original puede estar determinado por la posibilidad de sustitución del original en su mercado - debido al riesgo de confusión entre obra original y derivada, en casos de copia servil-, pero no por el efecto crítico. Así, la tolerancia que se exige en un sistema democrático supone también la necesidad de aceptar críticas duras o hasta corrosivas y los derechos de propiedad intelectual no pueden funcionar como un escudo frente a estas.

En el caso Campbell v. Acuff-Rose, la Corte Suprema sostuvo que la crítica mordaz que es propia de la parodia no podía ser considerada un tipo de daño al trabajo original, bajo el cuarto factor del fair use. ${ }^{32}$ De forma semejante, en el caso Leibovitz v. Paramount Pictures el Segundo Circuito de la Corte de Apelación sostuvo que el daño determinado por una posible pérdida de ganancia por parte de la demandante, derivada de la no disposición de las celebridades para ser fotografiadas por temor de sufrir parodias, no es un daño que se considere ilícito. ${ }^{33}$

Consideramos que podría ser útil rescatar el desarrollo de la jurisprudencia norteamericana sobre la cuarta condición del fair use, a fin de propo-

31 BERCOVITZ, Germán. Obra plástica y derechos patrimoniales de su autor. Madrid: Tecnos, 1997, p. 424.

32 "We do not, of course, suggest that a parody may not harm the market at all, but when a lethal parody, like a scathing theater review, kills demand for the original, it does not produce a harm cognizable under the Copyright Act. Because "parody may quite legitimately aim at garroting the original, destroying it commercially as $[\ldots]$ well as artistically» $[\ldots]$ the role of the courts is to distinguish between "[b]iting criticism that merely] suppresses demand [andl copyright infringement [which] usurps it.» [Campbell v. Acuff-Rose Music, Inc. Apartado II, D. (<http://laws.findlaw.com/US/000/ u10426.html>)l.

33 Leibovitz v. Paramount Pictures. Footnotes 7 (<http://laws.findlaw.com/2nd/ $977063 \mathrm{v} 2 . \mathrm{html}>$ ). 
ner nuevas lecturas del requisito establecido en nuestra norma nacional. Así, por ejemplo, podríamos calificar como una manifiesta forma de daño a la obra original la venta simultánea de copias serviles en el mercado potencial de la obra original. Al respecto, Díaz Alabart ${ }^{34}$ señala el caso de la demanda entablada por la Twentieth Century Fox Film Corporation contra la Anglo Almagamated Film Distributors Ltd. por el supuesto plagio de unos carteles en los que la demandada anunciaba sus películas, los cuales eran prácticamente idénticos a los utilizados por la demandante para anunciar las suyas. La única diferencia existente entre ambos carteles era que la demandada mostraba a sus actores y la demandante a los suyos. En su defensa, la demandada señaló que sus carteles constituían una parodia de los carteles de la demandante. Sin embargo, los jueces determinaron que el gran parecido de ambos carteles inducía a confusión al consumidor, por lo que no podían tomarse como una parodia lícita. A similar conclusión podría arribarse si, simultáneamente a la exhibición de una película cómica, otra productora cinematográfica pusiese en cartelera una parodia de ella, pues el público podría verse confundido debido a que comparten el mismo género (comedia).

\subsection{El uso de la parodia implica una remuneración al autor de la obra original}

Este requisito supone que al utilizarse una obra original a fin de efectuarse una parodia, se deben reconocer los legítimos derechos patrimoniales del autor de la obra parodiada. En la práctica, durante la negociación entre la persona que desee realizar la parodia y el autor, este último conocerá a priori las transformaciones que sufrirá su obra, de modo tal que podrá evaluar si la misma infiere a él o a su obra algún tipo de daño o confusión. Obviamente, si se ha extinguido el plazo de duración del derecho patrimonial ya no es necesario efectuar pago alguno, sin perjuicio del respeto de los derechos morales del autor.

Cabe señalar que, frente al debate existente en ciertos países cuya normatividad no contempla de manera expresa una remuneración para el autor de la obra parodiada, la doctrina ha considerado que este requisito deriva de las disposiciones generales vinculadas al derecho patrimonial del autor. Al respecto, el artículo 36 de la Ley peruana de Derechos de Autor establece que "el autor tiene el derecho exclusivo de hacer o autorizar las traducciones, así como las adaptaciones, arreglos y otras transformaciones de su obra, inclusive el doblaje y el subtituladon, lo cual sin duda trae como

34 Díaz Alabart, op. cit., p. 682. 
correlato una remuneración. Sobre el particular, Ricardo Antequera opina que «el que la ley permita la parodia sin el consentimiento del autor, no implica que dicho uso pueda hacerse a título gratuitom. ${ }^{35}$

No obstante lo establecido en nuestra norma, el requisito de la remuneración para todo tipo de parodias, sin distinción, puede desincentivar su creación $y$, hasta cierto punto, otorgar una suerte de coraza frente a las críticas al autor de la obra original, inadmisible en el contexto de una sociedad democrática y tolerante. Lo más grave de esta disposición, sin embargo, es que puede constituir una verdadera censura previa de la libertad de expresión. Cuando la parodia es la única forma de expresar una idea - supuesto que encaja dentro de la fórmula establecida por la tesis de la unión ideaexpresión de la doctrina norteamericana- la obligación de remunerar al autor de la obra original puede significar un obstáculo insalvable para el parodista que no tiene los recursos económicos necesarios para satisfacer dicho requisito. Con ello, su expresión -únicamente posible de ser manifestada por medio de la parodia — estaría sometida a un impedimento de origen, establecido por la ley.

Por ello, consideramos que deben proponerse alternativas al actual sistema de remuneración establecido en la Ley de Derechos de Autor a favor del autor de la obra parodiada. Así, aunque no negamos la necesidad y justicia de dicho requisito, este debería ser evaluado por el juzgador en cada caso concreto en los que pueda encontrarse en conflicto el derecho de propiedad intelectual del autor y el derecho a la libertad de expresión del parodista, realizándose una adecuada ponderación entre ambos derechos y tomando en cuenta ciertos criterios -que rescatamos de la jurisprudencia y doctrina norteamericana- como los siguientes: el hecho de que la parodia constituya una eventual crítica del trabajo original; el tipo de uso de la parodia, es decir, si se trata de un uso meramente comercial que busca un simple provecho económico o, más bien, una forma de expresión artística o referida a temas de interés público; o si constituye la única forma de expresar una determinada idea. Así, por ejemplo, si la parodia de una obra ha sido elaborada únicamente para vender un producto o un servicio - sin intención de comentar o criticar el original ni de realizar una crítica política o social sobre algún tema de interés público- su autor debería pagar una remuneración al autor de la obra original por el aprovechamiento comercial que obtiene de su uso. El siguiente ejemplo podría ilustrar este último supuesto: un anuncio publicitario en el cual se

35 ANTEQUERA, Ricardo. La obra como objeto del Derecho de Autor. Documento elaborado para el II Curso Intensivo de Posgrado en Derecho de Autor y Derechos Conexos de la Universidad de Buenos Aires (14 de julio al 1 de agosto de 2003), p.17. 
parodie un conocido personaje de caricaturas de manera tal que muestre una abierta preferencia por el producto o servicio anunciado.

\section{Parodia y dilución de marcas}

Dentro de los tipos de signos distintivos, generalmente son las marcas notoriamente conocidas ${ }^{36}$ las utilizadas en parodias de diversa índole, debido principalmente a la alta carga informativa que poseen y a su gran nivel de recordación por parte del consumidor. Al respecto, Monteagudo ${ }^{37}$ sostiene que «las marcas renombradas ${ }^{38}$ precisamente por su amplio contenido informativo y representativo pueden servir para resumir conceptualmente determinados fenómenos culturales, grupos de personas o formas de vida y, por tanto, constituyen un instrumento apto para la expresión de opiniones concernientes a estos aspectos».

Sobre los impedimentos de uso de una marca registrada, la Decisión 486 de la Comisión de la Comunidad Andina (Régimen Común sobre

36 El artículo 228 de la Decisión 486 señala que, para determinar la notoriedad de un signo distintivo, se tomará en consideración entre otros, los siguientes factores:

a) el grado de su conocimiento entre los miembros del sector pertinente dentro de cualquier País Miembro;

b) la duración, amplitud y extensión geográfica de su utilización, dentro o fuera de cualquier País Miembro;

c) la duración, amplitud y extensión geográfica de su promoción, dentro o fuera de cualquier País Miembro, incluyendo la publicidad y la presentación en ferias, exposiciones u otros eventos de los productos o servicios, del establecimiento o de la actividad a los que se aplique;

d) el valor de toda inversión efectuada para promoverlo, o para promover el establecimiento, actividad, productos o servicios a los que se aplique;

e) las cifras de ventas y de ingresos de la empresa titular en lo que respecta al signo cuya notoriedad se alega, tanto en el plano internacional como en el del País Miembro en el que se pretende la protección;

f) el grado de distintividad inherente o adquirida del signo;

g) el valor contable del signo como activo empresarial;

h) el volumen de pedidos de personas interesadas en obtener una franquicia o licencia del signo en determinado territorio;

i) la existencia de actividades significativas de fabricación, compras o almacenamiento por el titular del signo en el País Miembro en que se busca protección;

j) los aspectos del comercio internacional; $o$,

k) la existencia y antigüedad de cualquier registro o solicitud de registro del signo distintivo en el País Miembro o en el extranjero.

37 Monteacudo, Montiano. La protección de la marca renombrada. Madrid: Civitas, 1995, p. 271.

38 La legislación comparada, a diferencia de la nacional, distingue diversos tipos de notoriedad de marcas. Al respecto véase PACON, Ana María. "Marcas notorias, marcas renombradas, marcas de alta reputación". Derecho PUC, n. ${ }^{\circ} 47$, Lima, 1993. 
Propiedad Industrial) establece, en su artículo 157, que el registro de una marca no confiere a su titular el derecho de prohibir a un tercero usar esta para anunciar, inclusive en publicidad comparativa, ${ }^{39}$ ofrecer en venta o indicar la disponibilidad de productos o servicios legítimamente marcados, o para indicar la compatibilidad de piezas de recambio o de accesorios, siempre que tal uso sea de buena fe, se limite a propósitos informativos y no sea susceptible de inducir a confusión al consumidor. Asimismo, el artículo el artículo 226 de la Decisión 486 indica que nos encontramos ante un uso no autorizado del signo distintivo notoriamente conocido cuando puedan producirse alguno de los efectos siguientes:

a) riesgo de confusión o de asociación con el titular del signo, o con sus establecimientos, actividades, productos o servicios;

b) daño económico o comercial injusto al titular del signo por razón de una dilución de la fuerza distintiva o del valor comercial o publicitario del signo; $o$,

c) aprovechamiento injusto del prestigio o del renombre del signo.

La dilución de una marca notoria consiste en la progresiva pérdida de su poder distintivo o publicitario, lo cual puede producirse, entre otros factores, cuando la marca es utilizada para distinguir productos o servicios diferentes, cuando la marca se torna común o genérica, ${ }^{40}$ cuando la marca se usa de manera adhesiva o parasitaria,${ }^{41}$ o cuando la marca es utilizada en contextos distintos a los concurrenciales, como es el caso de la parodia de marcas.

Respecto a la parodia de marcas, la jurisprudencia norteamericana — como hemos visto- ha tenido un desarrollo importante que merece ser tomado

39 Precisamente sobre la ilicitud del uso de afirmaciones subjetivas en publicidad comparativa que constituyen supuestos de explotación de reputación ajena, la Sala de Defensa de la Competencia del Tribunal del INDECOPI emitió la Resolución 0547-2003/TDCINDECOPI (precedente de observancia obligatoria) de fecha 3 de diciembre de 2003. Entre otros puntos, el precedente estableció: "La publicidad comparativa pierde su carácter informativo cuando el anunciante utiliza opiniones o afirmaciones no comprobables, es decir, de carácter subjetivo, ya que es imposible para el consumidor comprobar si las supuestas ventajas anunciadas existen en realidad. Esta falta de carácter informativo, es decir, de objetividad, provoca que el competidor aludido sufra un daño - materializado en la detracción potencial o real de clientela- - sin que el consumidor se vea beneficiado por ello. El efecto neto de este tipo de publicidad comparativa es negativo y, por ello, inaceptable para el modelo social de represión de la competencia desleal al que responde el ordenamiento nacional en materia publicitaria”.

* Para un visión económica del derecho de marcas véase LANDEs, William y Richard POSNER. The EConomic Structure of Intellectual Property Law. Massachussets: Harvard University Press, 2003.

4t Un claro ejemplo de este uso se da en la publicidad comparativa subjetiva, la cual comentamos anteriormente. 
en cuenta. No obstante, las decisiones que han tomado los tribunales norteamericanos sobre este tema no han sido uniformes. En efecto, conforme apunta Monteagudo, ${ }^{42}$ en algunos casos se prefirió la manifestación de la libertad de expresión mediante una parodia crítica en detrimento de las pretensiones del titular de la marca, mientras que en otras oportunidades, cuando se verificó el riesgo de confusión o de aprovechamiento comercial, predominó el interés del titular de la marca.

Un caso en el que se optó por privilegiar el derecho a la libertad de expresión es Girl Scouts of the United States v. Personality Posters Manufacturing $\mathrm{Co}^{43} \mathrm{La}$ demandada había publicado un afiche donde se apreciaba la figura de una joven embaraza vistiendo el uniforme de una Girl Scout, junto con la frase «Be Prepared». La corte señaló como sustento a la Primera Enmienda para no amparar al titular de la marca.

Por el contrario, podemos citar tres ejemplos en los que los tribunales norteamericanos hicieron primar el interés del titular del signo distintivo:

1. La empresa titular de la conocida marca de champán Dom Perignon demandó a un fabricante de rosetas de maíz (porcorn) que distinguía sus productos bajo el signo "Dom Popignon Champop", los cuales eran colocados en envases que tenían forma de botellas de champaña. La Corte sostuvo que la parodia podía llevar a confusión a los consumidores, pues estos eventualmente creerían que las rosetas de maíz se fabricaban en virtud de una licencia de uso de marca otorgada por los titulares del champán Dom Perignon. ${ }^{44}$

2. El lema comercial "Where there's life... there's bugs" fue utilizado en Estados Unidos por un fabricante de insecticidas, parodiando así el lema de la cerveza Budweiser "Where there's life ... there's Bud». La Corte señaló la existencia de una asociación desagradable entre bugs (insectos) y la cerveza. ${ }^{45}$

3. Se prohibió el uso de la frase "Enjoy Cocaine» en un afiche que utilizaba el mismo estilo y distribución de colores que utilizan los titulares de la marca Coca-Cola con el lema "Enjoy Coca-Cola". La Corte consideró que la asociación de la marca Coca-Cola con una droga generaría connotaciones no deseadas a la imagen creada alrededor de la marca. ${ }^{46}$

42 MONTEAGUdo, op. cit., p. 127-128.

43 Al respecto, véase LANCVARDr, Arlen. "Protected Marks and Protected Speech». Villanova University Law Review, n. ${ }^{\circ}$ 36, 1991.

4 Al respecto, véase LOTT, Leslie y Hutton BRETT. Trademark Parody (<http:// www.patentfla.com/articles/trademark_parody.htm>).

45 Al respecto, véase WILF, Steven. "Who Authors Trademarks?». Cardozo Arts \& Entertainment Law Journal, n. ${ }^{\circ} 17,1999$. En el presente caso, estimamos que la corte también valoró el uso estrictamente comercial (ausente de crítica alguna) que se estaba dando al lema de la cerveza Budweiser.

* PaCón, op. cit., p. 350. 
Consideramos que la parodia de una marca podría reputarse lícita en la medida que por medio de ella se estableciera una crítica o comentario sobre algún tema de relevancia social, siempre y cuando no se produzca riesgo de confusión, dilución innecesaria o manifiesto aprovechamiento comercial del signo distintivo en cuestión. Un ejemplo de lo antes dicho podría constituir la parodia que hace "Kentucky Fried Cruelty" de la marca "Kentucky Fried Chicken", por la cual se critica la crueldad ${ }^{47}$ a la que son sometidos los pollos destinados a la conocida cadena de comida rápida.

\section{Reflexión final}

Es mucho lo que se puede discutir sobre el tema de la parodia en el derecho de propiedad intelectual, más aún cuando constituye un ámbito prácticamente inexplorado por parte de la doctrina nacional. Aunque, inicialmente, puede aparecer como un tema poco llamativo a su estudio, hemos podido demostrar mediante este trabajo lo recurrente de su uso en la realidad así como la actualidad y relevancia de su problemática, más aún cuando entra en relación con el derecho a la libertad de expresión que le es inherente.

En este artículo, hemos presentado algunas de las principales propuestas y discusiones respecto al tema de la parodia, tanto en el derecho de propiedad intelectual continental (circunscribiéndonos al derecho de autor y al derecho de marcas) como en el sistema del copyright norteamericano. Consideramos fundamental analizar estas a partir del marco normativo nacional referido al tema, en el cual podemos reconocer aciertos importantes (así, por ejemplo, consideramos adecuada la concepción amplia de la parodia que recoge nuestra ley, la que, a diferencia del sistema norteamericano, no distingue entre parodia y sátira, y no exige como un requisito de su licitud el hecho de que constituya una necesaria crítica del trabajo original parodiado), pero en el que, creemos, también es importante introducir algunas modificaciones, esencialmente en lo que respecta al tema de la remuneración del autor de la obra original previsto en el artículo 49 de la Ley de Derechos de Autor.

Más allá de las necesarias modificaciones a la legislación nacional, son los jueces - aquí nos referimos, en forma amplia, tanto a la justicia ordinaria como a los órganos administrativos encargados de resolver en materia de propiedad intelectual- los llamados a cumplir una labor especialmente relevante en los casos en que se deba determinar la licitud de una parodia,

Véase mayor información sobre las actuales investigaciones con relación a dicho trato cruel, en: <http://www.kfccruelty.com/s. 
sobre todo cuando esta pueda considerarse como una manifestación del derecho a la libertad de expresión. Así, y en la medida que estarán en juego dos derecho fundamentales reconocidos por nuestra Constitución, será la ponderación del juez, en cada caso concreto, la que nos permita arribar a una decisión adecuada. Para tal efecto, el juez deberá tomar en consideración ciertos criterios orientadores - recogidos, como vemos, del amplio desarrollo dado al tema por la doctrina y la jurisprudencia extranjera, pero que deberán leerse a la luz de los principios y reglas propios de nuestro sistema- como la cantidad de la creación original o de la marca tomada por el parodista; el efecto crítico de la parodia, ya sea respecto a la obra o marca original, o sobre un tema o asunto de interés público; el posible daño a la obra original o marca (principalmente en el caso de dilución de marcas notorias), visto a la luz de los principios democráticos que rigen nuestro sistema jurídico, como el principio de tolerancia; y el tipo de uso de la parodia, pues - sin desconocer el enorme contenido expresivo que pueden tener los usos comerciales- ${ }^{48}$ es lógico pensar que no podrá dársele la misma protección a una parodia que implique una expresión de tipo artística o sobre temas de interés público, que a una parodia comercial dirigida exclusivamente a incentivar las ventas de un producto o servicio y que, eventualmente, esté aprovechándose, por ejemplo, del poder de ventas de un personaje protegido por los derechos de autor o de la enorme fuerza distintiva y publicitaria de una marca notoria.

* Como señalaba el juez Kozinski en su voto disidente en el caso White v. Samsung Electronics America, Inc. (1993), aunque el commercial speech puede ser menos protegido por la Primera Enmienda que el non commercial speech, por ello no deja de estar protegido, pues el commercial speech tiene un profundo efecto en nuestra cultura y nuestras actitudes. Así, por ejemplo, los avisos de apariencia neutral influyen en las actitudes políticas y sociales de la gente y levantan controversias políticas. Como dice el juez: "In our pop culture, where salesmanship must be entertaining and entertainment must sell, the line between the commercial and noncommercial has not merely blurred, it has disappeared". Fundamento VI (<http://laws.findlaw.com/9th/2/989/1512.html ). 